\title{
CONTROLE DE Cerconota anonella (SEPP.) (LEP.: OECOPHORIDAE) E DE Bephratelloides pomorum (FAB.) (HYM.: EURYTOMIDAE) EM FRUTOS DE GRAVIOLA (Annona muricata L.) ${ }^{1}$
}

\author{
SÔNIA MARIA FORTI BROGLIO MICHELETTI², ANDRÉ GUSTAVO SANTOS DE MELO AGRA ${ }^{3}$, \\ GERALDO VERÍSSIMO SOUZA BARBOSA ${ }^{3}$, FABIANO LEITE GOMES ${ }^{2}$
}

\begin{abstract}
RESUMO - Um experimento de campo foi realizado em Maceió, Estado de Alagoas, Brasil, para avaliar os controles químico e mecânico de Cerconota anonella (Sepp.) (Lepidoptera: Oecophoridae) e de Bephratelloides pomorum (Fab.) (Hymenoptera: Eurytomidae), as pragas-chave da gravioleira, Annona muricata L. O delineamento experimental utilizado foi o inteiramente casualizado, com 9 tratamentos e 20 repetições. Foram avaliadas as seguintes variáveis nos frutos: números de orifícios causados pelas pragas, peso, comprimento e diâmetro. Em cada tratamento, observaram-se a percentagem de frutos colhidos e os custos unitários. Os melhores resultados foram obtidos com o saco plástico comum e com o saco plástico perfurado.
\end{abstract}

Termos para indexação: Insecta, broca-da-polpa, broca-da-semente, controle, Annona muricata

\section{CONTROL OF Cerconota anonella (SEPP.) (LEP.: OECOPHORIDAE) AND Bephratelloides pomorum (FAB.) (HYMENOPTERA: EURYTOMIDAE) IN SOURSOP (Annona muricata L.)}

\begin{abstract}
A field experiment was carried out in Maceió, State of Alagoas, Brazil to evaluate the controls chemical and mechanical of Cerconota anonella (Sepp.) (Lep.: Oecophoridae) and Bephratelloides pomorum (Fab.) (Hym.: Eurytomidae), the most important pests of soursop, Annona muricata L. Nine treatments were tested with twenty replications in a completely randomized design. The variables analyzed at the fruit were: hole caused by insects, weight, length, diameter and cost price. Also were evaluated the fruits cropped percentage. The best results were obtained using plastic bags and perforated plastic bags.
\end{abstract}

Index terms: Insecta, fruit borer, seed borer, control, Annona muricata

\section{INTRODUÇÃO}

A crescente demanda e o interesse pela polpa por parte do consumidor e das indústrias de suco, sorvetes e doces, justificam a inclusão da graviola no rol das frutas tropicais brasileiras de maior aceitação comercial, sendo amplamente cultivada nas regiões Norte, Nordeste, Centro-Oeste e Sudeste (Junqueira et al., 1996). Vários problemas fitossanitários, entretanto, limitam o cultivo dessa planta. A broca-do-fruto, Cerconota anonella (Sepp.) (Lepidoptera.: Oecophoridae) e a broca-da-semente, Bephratelloides pomorum (Fab.) (Hymenoptera: Eurytomidae) são consideradas as pragas mais importantes, pelos danos expressivos que causam direta e indiretamente à cultura.

Algumas medidas de controle culturais para combater $C$. anonella, como catação e queima ou enterrio dos frutos atacados, poda de formação e rejuvenescimento e também as medidas físicas, com a utilização de armadilhas luminosas, têm sido indicadas (Melo et al., 1983; Calzavara \& Muller, 1987; EMATER/AL, 1989).
A utilização de invólucros que não prejudiquem o desenvolvimento normal dos frutos e garantam proteção contra a praga tem sido incentivada. Esta prática é considerada profilática e assegura bom controle, se for iniciada assim que os frutos tiverem aproximadamente $2,5 \mathrm{~cm}$ de comprimento (Doesburg, 1964; Melo et al., 1983; McComie, 1987; Carneiro \& Bezerril, 1993; Manica, 1994). Embora Pinto \& Genu (1984) tenham usado inseticidas carbamatos e Bustillo \& Peña (1992) coberto os frutos com saco plástico aberto em uma das extremidades e tratado com clorpirifós, o êxito do controle foi pouco expressivo.

Para B. pomorum, foram recomendadas as seguintes medidas de controle: inspeção semanal do pomar, a partir do período de frutificação, coletando, queimando ou enterrando os frutos atacados a uma profundidade de $50 \mathrm{~cm}$; ensacamento dos frutos ainda pequenos, com invólucros de diversos materiais. Indica-se, também, a cada 15-20 dias, a pulverização dirigida aos frutos ainda pequenos, com inseticidas à base de trichlorfon, monocrotophos ou endossulfan, nas concentrações de $0,10 \%$, $0,05 \%$ e $0,08 \%$, respectivamente, ou com uma calda à base de

1 (Trabalho 235/2000). Recebido: 23/10/2000. Aceito para publicação: 11/09/2001. Pesquisa financiada pela FAPEAL/SEBRAE/CNPq.

2 CECA/UFAL, Professores do Departamento de Fitotecnia e Fitossanidade, Campus Delza Gitaí, BR 104, km 85, 57.100-000, Rio Largo, AL. Email: vlamiche@sistecnet.com.br

3 CECA/UFAL, bolsistas da FAPEAL/CNPq

Rev. Bras. Frutic., Jaboticabal - SP, v. 23, n. 3, p. 722-725, dezembro 2001 
melaço $(10 \mathrm{ml})$, sementes de graviola trituradas $(10 \mathrm{~g})$, monocrotophos $(5 \mathrm{ml})$ e água $(10 \mathrm{ml})$ (Junqueira et al., 1996; Braga Sobrinho et al., 1998).

Após a entrada dessas brocas nos frutos, entretanto, o controle químico torna-se ineficaz e, quando os piretróides são usados, continuadamente, ocorre aumento de danos causados por ácaros. Os inseticidas, quando usados preventivamente, além de contaminar o meio ambiente, eliminam os inimigos naturais e os vários polinizadores, que são importantes, pois a cultura apresenta os problemas fisiológicos da dicogamia protogínica. Isto significa que, mesmo sendo planta hermafrodita, a autopolinização é rara, pois os estigmas amadurecem antes dos estames.

O tamanho do fruto para início do controle é um aspecto que merece ser ressaltado, pois Broglio- Micheletti (1999) utilizou comprimentos entre 1 a $3 \mathrm{~cm}$ e 6 a $10 \mathrm{~cm}$. Sugeriu, no entanto, que um tamanho intermediário seria razoável, já que, com esses tamanhos, ocorreram alguns inconvenientes, como excesso de abortamentos para 1 a $3 \mathrm{~cm}$ e infestação pré-controle para os comprimentos maiores.

Considerando que a gravioleira tem grande destaque na fruticultura da região nordestina brasileira, e a importância dessas pragas, são necessários estudos visando a estabelecer formas mais viáveis de seus controles.

\section{MATERIAL E MÉTODOS}

Os efeitos de diferentes formas de controle da boca-dofruto e da broca-da-semente foram testados em plantação de graviola localizada no Sítio Aldeia Verde, em Maceió-AL, no período compreendido entre outubro/1999 a fevereiro/2000.

Os tratamentos utilizados foram: 1- frutos sem proteção (testemunha); 2 - saco de papel kraft ( $43 \mathrm{~cm}$ de comprimento $\mathrm{x}$ $24 \mathrm{~cm}$ de largura); 3 - saco plástico comum fechado na extremidade inferior, apenas com alguns orifícios feitos para permitir o escoamento da água ( $49 \mathrm{~cm}$ de comprimento x $28 \mathrm{~cm}$ de largura); 4 - saco plástico comum aberto na extremidade inferior $(49 \mathrm{~cm}$ de comprimento x $28 \mathrm{~cm}$ de largura; 5 - saco plástico perfurado $(49 \mathrm{~cm}$ de comprimento $\mathrm{x} 28 \mathrm{~cm}$ de largura); 6- saco de papel impermeável nas duas faces ( $45 \mathrm{~cm}$ de comprimento x $32 \mathrm{~cm}$ de largura); 7pulverização dos frutos semanal e localizada, com triflumuron $250 \mathrm{~g} / \mathrm{kg}$, sendo a dosagem $100 \mathrm{~g} / \mathrm{há}$; 8- pulverizações com triflumuron $250 \mathrm{~g} / \mathrm{kg}$, na dosagem $100 \mathrm{~g} / \mathrm{ha}$, sendo posteriormente os frutos ensacados com saco plástico perfurado; 9- pulverização dos frutos semanal e localizada, com imidacloprid $700 \mathrm{~g} / \mathrm{kg}$, sendo a dosagem $100 \mathrm{~g} / \mathrm{ha}$. Os tratamentos foram aplicados em frutos de 4 a $6 \mathrm{~cm}$ de comprimento, repetidos 20 vezes, em plantas diferentes.

Antes de realizar quaisquer tratamentos, certificava-se de que não houvesse insetos na superfície dos frutos. Se isso ocorresse, eles eram retirados com pincel. Os sacos foram presos aos ramos acima dos frutos, por meio de arame plastificado. Semanalmente, até a colheita, foram realizadas inspeções para a verificação de queda de frutos e/ou danificação do invólucro. No caso do tratamento com os inseticidas, considerou-se o intervalo de segurança de 10 dias que antecedem a colheita, para suspender a aplicação dos produtos em campo.

Na ocasião da colheita, foram avaliadas as características: número de orifícios causados por C. anonella e por B. pomorum, peso, comprimento e diâmetro dos frutos. Realizou-se a análise estatística dos dados, aplicando-se o teste da DMS para comparar as médias dos tratamentos das variáveis peso, comprimento e diâmetro dos frutos e o teste não-paramétrico de Kruskal-Wallis para comparar as médias dos tratamentos da variável número de orifícios ocasionados por C. anonella e por B. pomorum. Avaliouse também a percentagem de frutos colhidos para cada tratamento. Fez-se, ainda, a análise econômica.

\section{RESULTADOS E DISCUSSÃO}

$\mathrm{Na}$ Tabela 1, estão apresentados os resultados médios do número de orifícios ocasionados por $C$. anonella e por $B$. pomorum, peso, comprimento, diâmetro, percentagem de frutos colhidos e custos unitários para proteger os frutos de graviola. Nota-se que os tratamentos que tiveram percentagem de frutos colhidos acima de $80 \%$ foram: saco plástico perfurado $(85,00)$ e saco plástico fechado $(90,00)$.

Considerando-se a variável número de orifícios ocasionados por $C$. anonella, verifica-se que os tratamentos saco de papel kraft, saco plástico aberto e saco plástico perfurado não diferiram estatisticamente da testemunha, sendo semelhantes entre si. Já os tratamentos saco de papel impermeável, saco plástico fechado, triflumuron, triflumuron + saco plástico perfurado e imidacloprid apresentaram expressiva redução do número de orifícios e não diferiram entre si.

Em relação ao número de orifícios causados por $B$. pomorum, nenhum tratamento diferiu estatisticamente da testemunha e do imidacloprid, porém havendo significativa redução no número entre o saco de papel kraft, saco de papel impermeável, saco plástico fechado, saco plástico aberto, saco plástico perfurado e triflumuron + saco plástico perfurado, em relação ao triflumuron.

A característica peso dos frutos apresentou a média geral no ensaio de $1,217 \mathrm{~kg}$. Os tratamentos triflumuron e o imidacloprid diferiram estatisticamente dos demais. Em seguida, os tratamentos saco plástico perfurado, saco plástico fechado, o triflumuron + saco plástico perfurado, saco plástico aberto, saco de papel impermeável e de papel kraft, com pesos acima da média, não diferiram entre si. A testemunha apresentou peso abaixo da média $(0,99 \mathrm{~kg})$ e diferiu dos tratamentos saco de papel kraft, saco de papel impermeável e triflumuron.

Os frutos protegidos com o saco de papel kraft, saco de papel impermeável, triflumuron + saco plástico perfurado, saco plástico aberto e saco plástico fechado foram os que tiveram os seus comprimentos acima da média, não diferindo estatisticamente entre si. Já os tratamentos testemunha, saco plástico perfurado, triflumuron e imidacloprid apresentaram seus comprimentos abaixo da média. Em relação aos diâmetros, não foi observada diferença estatística entre os tratamentos.

A embalagem de papel kraft apresentou a desvantagem de dificultar a colheita, pois externamente aos invólucros havia gafanhotos e internamente, formigas Camponotus sp. (Hymenoptera: Formicidae), além do que ficava difícil de se determinar o ponto de colheita. Os frutos que se desenvolveram nestas embalagens tenderam a ser amarelados. A embalagem de papel impermeável teve a desvantagem de ter de ser montada, a partir de folhas individuais, pois, em Alagoas, elas não são comercializadas já prontas para o uso. 
TABELA 1 - Número de orifícios ocasionados por Cerconota anonella e por Bephratelloides pomorum, peso, comprimento, diâmetro, percentagem de frutos colhidos e custos unitários para proteger os frutos de graviola. Médias de 20 repetições. Sítio Aldeia Verde, Maceió-AL, outubro/1999 a fevereiro 2000.

\begin{tabular}{|c|c|c|c|c|c|c|c|}
\hline Tratamento & $\begin{array}{l}\mathrm{N}^{\mathrm{o}} \text { de orifício } \\
(\text { C. anonella })^{1}\end{array}$ & 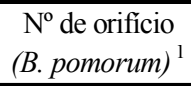 & $\begin{array}{l}\text { Peso }^{2} \\
(\mathrm{~kg})\end{array}$ & $\begin{array}{c}\text { Comprimento } \\
(\mathrm{cm})\end{array}$ & $\begin{array}{c}\text { Diâmetro }^{2} \\
(\mathrm{~cm})\end{array}$ & $\begin{array}{c}\text { Fruto } \\
\text { colhido }(\%)\end{array}$ & $\begin{array}{c}\text { Custo/fruto tratado } \\
(\mathrm{R} \$)\end{array}$ \\
\hline Testemunha & $1,90 \mathrm{a}$ & $32,70 \mathrm{ab}$ & $0,99 \mathrm{~b}$ & $17,00 \mathrm{bcd}$ & $33,00 \mathrm{abc}$ & 55,00 & - \\
\hline Saco de papel kraft & $1,75 \mathrm{ab}$ & $8,00 \mathrm{~b}$ & $1,49 \mathrm{a}$ & $20,00 \mathrm{a}$ & $37,00 \mathrm{abc}$ & 80,00 & 0,070 \\
\hline Saco de papel impermeável & $0,38 \mathrm{~b}$ & $6,12 b$ & $1,40 \mathrm{a}$ & $20,00 \mathrm{abd}$ & $37,00 \mathrm{abc}$ & 80,00 & 0,080 \\
\hline Saco plástico fechado & $0,44 \mathrm{~b}$ & $3,47 \mathrm{~b}$ & $1,36 a b$ & $21,00 \mathrm{a}$ & $36,00 \mathrm{abc}$ & 90,00 & 0,063 \\
\hline Saco plástico aberto & $1,33 a b$ & $8,00 \mathrm{~b}$ & $1,37 \mathrm{ab}$ & $21,00 \mathrm{a}$ & $36,00 \mathrm{abc}$ & 70,00 & 0,063 \\
\hline Saco plástico perfurado & $1,75 \mathrm{ab}$ & $3,23 \mathrm{~b}$ & $1,27 \mathrm{ab}$ & $19,00 \mathrm{abd}$ & $36,00 \mathrm{abc}$ & 85,00 & 0,115 \\
\hline Triflumuron $^{4}$ & $0,37 \mathrm{~b}$ & $34,00 \mathrm{a}$ & $0,76 \mathrm{c}$ & $16,00 \mathrm{~cd}$ & $31,00 \mathrm{c}$ & 40,00 & 0,434 \\
\hline Triflumuron $^{5}+$ Saco plástico perfurado & $0,36 \mathrm{~b}$ & $5,21 b$ & $1,37 \mathrm{ab}$ & $20,00 \mathrm{abd}$ & $38,00 \mathrm{ac}$ & 70,00 & 0,549 \\
\hline Imidacloprid & $0,29 \mathrm{~b}$ & $31,71 \mathrm{ab}$ & $0,94 \mathrm{bc}$ & $19,00 \mathrm{abcd}$ & $33,00 \mathrm{bc}$ & 35,00 & 0,457 \\
\hline Média geral & 0,952 & 14,715 & 1,217 & 19,222 & 35,222 & 67,222 & 0,229 \\
\hline Teste F & - & - & 2,347 & 2,208 & 1,749 & - & - \\
\hline QMR & - & - & 0,2770 & 0,0013 & 0,0032 & - & - \\
\hline $\mathrm{CV}$ & - & - & 41,21 & 18,59 & 15,71 & - & - \\
\hline Teste Kruskal Wallis & $26,54 * *$ & $52,14 * *$ & - & - & - & - & - \\
\hline
\end{tabular}

1) Médias de tratamentos seguidas pela mesma letra não diferem pelo teste de Kruskal-Wallis, ao nível de 5\% de probabilidade de erro.

2) Médias de tratamentos seguidas de mesma letra não diferem pelo teste da DMS, ao nível de 5\% de probabilidade de erro.

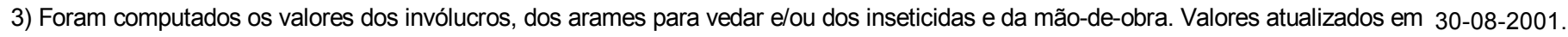

4) 12 aplicações

5) 1 aplicação

Quanto à análise econômica, os inseticidas testados possibilitaram custos superiores em relação aos demais tratamentos. Além da baixa eficiência no controle de B. pomorum, apresentaram o inconveniente de não serem registrados para a cultura em questão, podendo ocasionar, além disso, a contaminação ambiental, eliminação de inimigos naturais das pragas e de insetos polinizadores.

No Estado de Alagoas, em relação ao controle de pragas na cultura de graviola, o que prevalece é a utilização indiscriminada de agrotóxicos. Os produtores alegam que a técnica do ensacamento encarece o produto final, devido à mão-deobra que deve ser disponibilizada para tal fim. Mas, o que se observa no geral, é que quem realiza esta prática, tem os frutos apresentando qualidade superior, o que possibilita um efetivo retorno financeiro.

Como se observou pelos resultados obtidos, os sacos plásticos (comuns ou perfurados) foram as formas mais viáveis de controle de $C$. anonella e de B. pomorum, mas a limpeza do campo deve ser o primeiro passo para se ter sucesso com o controle de pragas em anonáceas, pois os adultos continuam a emergir de frutos infestados mesmo após eles terem caído ao solo, servindo como fonte de reinfestação. Estes frutos devem ser removidos das plantas e do solo que fica sob elas e serem completamente destruídos.

\section{CONCLUSÃO}

O ensacamento dos frutos com saco plástico comum ou com saco plástico perfurado (ambos com $49 \mathrm{~cm}$ de comprimento $\mathrm{x} 28 \mathrm{~cm}$ de largura) é a forma mais efetiva e econômica para controle de $C$. anonella e B. pomorum.

\section{AGRADECIMENTOS}

À FAPEAL/SEBRAE/CNPq, pelo auxílio financeiro. Ao Engenheiro Agrônomo Ricardo Luiz R. Ramalho Cavalcanti, pela gentileza em ceder a área para a realização do trabalho. Ao Prof. Dr. Luiz Carlos Forti, da UNESP/Botucatu, pela identificação das formigas.

\section{REFERÊNCIAS BIBLIOGRÁFICAS}

BRAGA SOBRINHO, R., OLIVEIRA, M.A.S., WARUMBY, J., MOURA, J.I.L. Pragas da gravioleira. In. BRAGA SOBRINHO, R., CARDOSO, J.E., FREIRE, F. das C.O. Pragas de fruteiras tropicais de importância agrícola. Brasília: EMBRAPA-SPI, 1998. 7, p. 131-141.

BROGLIO-MICHELETTI, S.M.F.B. Estudos sobre Cerconota anonella (Sepp., 1830)(Lep.: Oecophoridae) em gravioleira (Annona muricata L.) no Estado de Alagoas. Piracicaba, 1999. 88f. Tese (Doutorado em Ciências, Entomologia) - Escola Superior de Agricultura “Luiz de Queiroz”, Universidade de São Paulo.

BUSTILLO, A.E., PEÑA, J.E. Biology and control of the Annona fruit borer Cerconota anonella (Lepidoptera: Oecophoridae). Fruits, Paris, v.47, n.1, p. 81-84, 1992.

CALZAVARA, B.B.G.; MÜLLER, C.H. Fruticultura tropical: a gravioleira Annona muricata L. Belém: EMBRAPA/CPATU, 1987. 36p. (Documento, 47).

CARNEIRO, J. da S., BEZERRIL, E.F. Controle das brocas dos 
frutos (Cerconota anonella) e das sementes (Bephratelloides maculicolis) da graviola no planalto da Ibiapaba CE. Anais da Sociedade Entomológica do Brasil, Piracicaba, v. 22, n.1, p. 155160, 1993.

DOESBURG, P.H. van. Two insect pests of soursop in Surinam. Caribbean Agriculture, Puerto Rico, v. 3, p.797-803, 1964.

EMATER/AL. Proposta para um manejo integrado de pragas e doenças da anonicultura. Maceió: EMATER, 1989. 41p.

JUNQUEIRA, N.T.V.; CUNHA, M.M. da; OLIVEIRA, M.A.S.; PINTO, A.C. de Q. Graviola para exportação: aspectos fitossanitários. Brasília: EMBRAPA, 1996. 67 p. (Série publicações técnicas FRUPEX, 22).

MANICA, I. (Ed.) Fruticultura: cultivo das anonáceas ata, cherimólia e graviola. Porto Alegre: EVANGRAF, 1994. 117p.

McCOMIE, L.D. The soursop (Annona muricata L.) in Trinidad: its importance, pests and problems associated with pest control. Journal of the Agricultural Society of Trinidad and Tobago, n. 87, p. 42-55, 1987.

MELO, G. S. de; GONZAGA NETO, L.; MOURA, R.J.M. Cultivo da gravioleira (Annona muricata L.). Recife, IPA, 1983. 4p. (Instruções técnicas do IPA, 13).

PINTO, A.C. de Q., GENÚ, P.J. de C. Contribuição ao estudo técnico-científico da graviola (Annona muricata L.) In: CONGRESSO BRASILEIRO DE FRUTICULTURA, 7., 1984, Florianópolis., Anais. Florianópolis: SBF/ EMPASC, 1984. p.529546. 